\title{
Isolation and Characterization of Streptomyces venezuelae Mutants Blocked in Chloramphenicol Biosynthesis
}

\author{
By J. DOULL, ${ }^{1}$ Z. AHMED, ${ }^{2}$ C. STUTTARD ${ }^{1 *}$ AND L. C. VINING ${ }^{2}$ \\ Departments of Microbiology $y^{1}$ and Biology ${ }^{2}$, Dalhousie University, Halifax, Nova Scotia, \\ Canada $\mathrm{B} 3 \mathrm{H} 4 \mathrm{H} 7$
}

(Received 31 July 1984)

\begin{abstract}
Twelve Streptomyces venezuelae mutants blocked in chloramphenicol biosynthesis were isolated. Two of these (Cm1-1 and Cm1-12) were apparently blocked in the conversion of chorismic acid to $p$-aminophenylalanine and three $(\mathrm{Cml}-4, \mathrm{Cml-5}$ and $\mathrm{Cml}-8)$ accumulated $p$-aminophenylalanine and may have been blocked in the hydroxylation reaction that converted this intermediate to $p$-aminophenylserine. One mutant $(\mathrm{Cm} 1-2)$ accumulated D-threo-1-p-nitrophenyl-2-propionamido-1,3-propanediol and D-threo-1-p-nitrophenyl-2-isobutyramido-1,3-propanediol, indicating that chlorination of the $\alpha-N$-acyl group of chloramphenicol was blocked. The remaining six strains did not excrete any detectable chloramphenicol pathway intermediates.
\end{abstract}

\section{INTRODUCTION}

Extrachromosomal DNA appears to play a role in the production of antibiotics by some Streptomyces species. There is strong genetic evidence that structural genes coding for the biosynthesis of methylenomycin A in Streptomyces coelicolor A3(2) and Streptomyces violaceusruber are borne on plasmids SCP1 and pSV1, respectively (Kirby \& Hopwood, 1977; Aguilar \& Hopwood, 1982). Less conclusive evidence indicates that genes specifying the biosynthesis of tylosin in Streptomyces fradiae (Baltz et al., 1981), erythromycin in Streptomyces erythraeus (Weber et al., 1982), lankacidin in Streptomyces sp. 7434-AN (Hayakawa et al., 1979), streptomycin in Streptomyces griseus (Xue et al., 1978), and actinomycin in Streptomyces parvulus (Ochi \& Katz, 1980) are carried on plasmids, while Zippel et al. (1983) have invoked plasmid involvement in the regulation of turimycin biosynthesis in Streptomyces hygroscopicus. Another frequently quoted example is the presumed plasmid involvement in regulating chloramphenicol biosynthesis in Streptomyces venezuelae (Akagawa et al., 1979). In this organism, genes coding for chloramphenicol biosynthetic enzymes were reported to be linked to chromosomal markers; only regulatory genes were believed to be plasmid-borne. We have detected extrachromosomal DNA in only one of four strains of $S$. venezuelae examined, and elimination of the plasmid (pUC3) from this strain failed to alter antibiotic production (Ahmed \& Vining, 1983). We have also examined a chloramphenicol-producing strain of Streptomyces phaeochromogenes that contains plasmid pJV1, and have shown that the extrachromosomal DNA could be eliminated during protoplast formation and regeneration. Loss of the plasmid had no effect on chloramphenicol production (Doull et al., 1983). These results show that neither structural nor regulatory genes for chloramphenicol biosynthesis are located on the detectable plasmids of these organisms. However, the possibility remains that such genes are associated with plasmid DNA that was not detected by the procedures used in these experiments. The most decisive evidence on this question should be provided by demonstrating consistent linkage between genetic markers for antibiotic production and genes for primary pathways or other chromosomally-

\footnotetext{
Abbretiations: FUV, far ultraviolet light $(254 \mathrm{~nm})$; NUV, near ultraviolet light (366 nm); MOP, 8-methoxypsoralen.
} 
located markers. Therefore, we have isolated chloramphenicol-nonproducing mutants of $S$. venezuelae for use in mapping studies. This paper describes the isolation and characterization of such strains.

\section{METHODS}

Strains and growth conditions. Streptomyces venezuelae wild-type (prototrophic) strain ATCC 10712 (ISP 5230) was originally received from E. Wellington (Stuttard, 1982). Mutagenized spores were plated on MYM agar and minimal agar medium was used to test for growth factor requirements (Stuttard, 1982). Vegetative mycelial suspensions used as culture inocula were prepared by transferring a loopful of spores from a stock spore suspension in glycerol $(20 \%, \mathrm{v} / \mathrm{v})$ to $50 \mathrm{ml} \mathrm{GNY}$ medium and growing the culture for $48 \mathrm{~h}$ (Malik \& Vining, 1970). For chloramphenicol production, a $1 \%(\mathrm{v} / \mathrm{v})$ vegetative inoculum was added aseptically to medium containing glucose $(3 \%$, $\mathrm{w} / \mathrm{v}$ ), isoleucine $(0.75 \%)$ plus basal salts, and incubated at $27^{\circ} \mathrm{C}$ on a rotary shaker (Chatterjee et al., 1983).

Chemicals. p-Aminophenylalanine was obtained from Sigma. Chloramphenicol and D-threo-1-p-nitrophenyl-2acetamido-1,3-propanediol were gifts from Parke-Davis. The synthesis and properties of $2(S)$-dichloroacetamido-3-( $p$-acetamidophenyl)propan-1-ol have been described (Wat et al., 1971). $N$-Acetyl-p-nitrophenylalanine was synthesized as described by McGrath et al. (1968).

D-threo-1-p-Nitrophenyl-2-propionamido-1,3-propanediol was synthesized as described by Shirahata et al. (1972). The crude product in ethyl acetate was freed of unchanged D-threo-1-p-nitrophenyl-2-amino-1,3-propanediol by extraction with $2 \mathrm{M}-\mathrm{HCl}$. It was purified by preparative thin-layer chromatography (TLC) and crystallization from dichloroethane to give colourless needles, m.p. $108-110^{\circ} \mathrm{C} ; R_{F}$ (TLC, system A) $0 \cdot 24$. The ${ }^{1} \mathrm{H}-\mathrm{NMR}$ spectrum, recorded in deuterochloroform at $80 \mathrm{MHz}$ on a Varian model FT-80 spectrometer with tetramethylsilane as the internal reference, showed signals at $\delta 1 \cdot 04\left(\mathrm{t}, 3 \mathrm{H}, \mathrm{CH}_{3}, J_{\mathrm{CH}_{3}, \mathrm{CH}_{2}} 7 \cdot 6 \mathrm{~Hz}\right), 2 \cdot 15\left(\mathrm{q}, 2 \mathrm{H}, \mathrm{CH}_{2}, J_{\mathrm{CH}_{2}, \mathrm{CH}_{3}} 7 \cdot 6 \mathrm{~Hz}\right), 3 \cdot 00$ (bs, $1 \mathrm{H}, \mathrm{OH}), 3 \cdot 78-4 \cdot 30\left(\mathrm{ABC}, 3 \mathrm{H}, \mathrm{H}-1^{\prime}, \mathrm{H}-2^{\prime}\right), 5 \cdot 21\left(\mathrm{~d}, 1 \mathrm{H}, \mathrm{H}-3^{\prime}, J_{2^{\prime}} 3^{\prime} 3 \cdot 3 \mathrm{~Hz}\right), 6 \cdot 15\left(\mathrm{bd}, 1 \mathrm{H}, \mathrm{NH}, j_{\mathrm{NH}, 2^{\prime}} 7 \cdot 6 \mathrm{~Hz}\right), 7 \cdot 88$ $\left(\mathrm{AA}^{\prime} \mathrm{BB}^{\prime}, 4 \mathrm{H}, \mathrm{H}-2, \mathrm{H}-3, \mathrm{H}-5, \mathrm{H}-6, \Delta v_{\mathrm{AB}} 51 \cdot 1 \mathrm{~Hz}, \mathrm{~N}=J_{\mathrm{AB}}+J_{\mathrm{AB}^{\prime}}=8.8 \mathrm{~Hz}\right.$ ).

D-threo-1-p-Nitrophenyl-2-isobutyramido-1,3-propanediol was synthesized as follows. Isobutyric acid ( $88 \mathrm{mg})$ in dry acetone $(2 \mathrm{ml})$ containing triethylamine $(0.14 \mathrm{ml})$ was cooled to $-10^{\circ} \mathrm{C}$ in an ice-salt bath. Ethyl chloroformate $(0.7 \mathrm{ml})$ was added slowly with stirring and was followed, $25 \mathrm{~min}$ later, by a solution of D-threo-1-p-nitrophenyl-2-amino-1,3-propanediol $(212 \mathrm{mg})$ in acetone $(4 \mathrm{ml})$. The mixture was allowed to come to room temperature and, after $4 \mathrm{~h}$, was evaporated to dryness. The residue was dissolved in a mixture of ethyl acetate $(25 \mathrm{ml})$ and water $(5 \mathrm{ml})$. The product in the ethyl acetate layer was recovered and crystallized from water to give colourless needles, m.p. $130-131{ }^{\circ} \mathrm{C} ; R_{F}$ (TLC, system A) 0.30. The ${ }^{1} \mathrm{H}-\mathrm{NMR}$ spectrum, recorded as above, showed signals at $\delta 1.01\left(\mathrm{~d}, 3 \mathrm{H}, \mathrm{CH}_{3}, J_{\mathrm{CH}_{3}, \mathrm{H}} 6.9 \mathrm{~Hz}\right), 1.06\left(\mathrm{~d}, 3 \mathrm{H}, \mathrm{CH}_{3}, J_{\mathrm{CH}_{3}, \mathrm{H}} 6.9 \mathrm{~Hz}\right), 1.62(\mathrm{bs}, 1 \mathrm{H}, \mathrm{OH}), 2.27(\mathrm{qn}, 1 \mathrm{H}, \mathrm{CH}$, $\left.J_{\mathrm{H}, \mathrm{CH}_{3}} 6 \cdot 9 \mathrm{~Hz}\right), 3 \cdot 8-4 \cdot 3\left(\mathrm{ABC}, 3 \mathrm{H}, \mathrm{H}-1, \mathrm{H}-2^{\prime}\right), 5 \cdot 22\left(\mathrm{~d}, 1 \mathrm{H}, \mathrm{H}-3^{\prime}, J_{2^{\prime} 3^{\prime}} 3 \cdot 4 \mathrm{~Hz}\right), 6.06\left(\mathrm{bd}, 1 \mathrm{H}, \mathrm{NH}, J_{\mathrm{NH}, 2^{\prime}} 7 \cdot 5 \mathrm{~Hz}\right), 7 \cdot 88$ $\left(\mathrm{AA}^{\prime} \mathrm{BB}, 4 \mathrm{H}, \mathrm{H}-2, \mathrm{H}-3, \mathrm{H}-5, \mathrm{H}-6, \Delta v_{\mathrm{AB}} 51 \cdot 1 \mathrm{~Hz}, \mathrm{~N}=J_{\mathrm{AB}}+J_{\mathrm{AB}^{\prime}}=8 \cdot 8 \mathrm{~Hz}\right.$ ).

Thin-layer chromatography. Samples of chloramphenicol, its analogues and the ethyl acetate extracts of cultures before or after column chromatography, were applied to thin layers of silica gel F254 on glass plates; the chromatograms were developed in chloroform/methanol $(9: 1, \mathrm{v} / \mathrm{v} ;$ system A) or $n$-butanol/acetic acid/water $(12: 3: 5$, by vol.; system B). They were dried and sprayed in turn with aqueous stannous chloride and with a solution of $p$ dimethylaminobenzaldehyde in $2 \mathrm{M}-\mathrm{HCl}$. Zones containing aromatic nitro- or amino-compounds became yellow. For preparative chromatograms, $20 \times 20 \mathrm{~cm}$ plates of silica gel F254 (0.2 mm thickness) were used. The solvent was again chloroform/methanol $(9: 1, \mathrm{v} / \mathrm{v})$ but chromatograms were developed twice. Samples of $p$ aminophenylalanine and polar fractions from cultures were chromatographed on thin layers of cellulose MN300. The chromatograms were developed with $n$-butanol/ethanol/4 $\mathrm{M}$-ammonium hydroxide $(8: 1: 3$, by vol.; system C) or with $n$-butanol/acetic acid/water (12:3:5, by vol.; system D).

Mutagenesis. Four methods were used. (a) Irradiation with short-wavelength (254 nm) ultraviolet ight (FUV): spore suspensions in $0 \cdot 1 \mathrm{M}$-phosphate buffer, $\mathrm{pH} 7 \cdot 0$, were given sufficient exposure to produce approximately $99.9 \%$ killing and then plated on (i) MYM agar or (ii) MYM agar containing caffeine (500 $\mathrm{mg} \mathrm{ml}^{-1}$ ).

(b) Irradiation with long wavelength $(366 \mathrm{~nm})$ ultraviolet light (NUV) in the presence of 8-methoxypsoralen (MOP): spores suspended for $30 \mathrm{~min}$ in $0.015 \mathrm{M}$-phosphate buffer, $\mathrm{pH} 7.0$ containing MOP $\left(0.1 \mathrm{mg} \mathrm{ml}^{-1}\right)$ were irradiated to give about $1 \%$ c.f.u. survival and plated to obtain isolated colonies on MYM medium.

(c) Treatment with ethyl methanesulphonate (EMS): EMS (final concentration $70 \mathrm{mg} \mathrm{ml}^{-1}$ ) was added to a suspension of spores in $0.1 \mathrm{M}$-phosphate buffer and the mixture was shaken for $2 \mathrm{~h}$ at $27^{\circ} \mathrm{C}$. Spores were then collected on a membrane filter, washed with $250 \mathrm{ml}$ phosphate buffer and resuspended in a small volume of the buffer. Finally, they were plated to obtain isolated colonies on MYM agar.

Isolation of chloramphenicol-nonproducing mutants. Colonies that grew from mutagenized spores were allowed to sporulate and then streaked in patches on fresh MYM agar (five equally spaced patches per $9.0 \mathrm{~cm}$ diameter plate). The patched colonies were grown at $27^{\circ} \mathrm{C}$ until they sporulated (3-4 d); the plates were then carefully overlaid between the patches with soft $(0.5 \%, \mathrm{w} / \mathrm{v}) \mathrm{GNY}$ agar seeded with Micrococcus luteus. The overlaid plates were 
incubated overnight and examined for patches showing no inhibition of growth of the indicator bacteria. Inocula from such patches were restreaked on MYM agar to obtain single colonies which were again tested using the bioassay procedure. Isolates that still failed to inhibit the growth of $M$. luteus were then grown in chloramphenicolproduction medium for $7 \mathrm{~d}$ and mycelia were removed by centrifugation. The supernatant fluids were examined for the presence of aromatic nitro- or amino-compounds by the colorimetric procedure of Levine $\&$ Fischbach (1951). Those giving positive tests were extracted with ethyl acetate, initially at neutral pH and again after acidification to $\mathrm{pH} 2$. The extracts were concentrated separately and examined by TLC.

Compounds $A, B$ and $C$ from mutant $C \mathrm{ml}-2$. The supernatant fluid (21) from cultures of mutant $\mathrm{Cm} 1-2$ grown in chloramphenicol-production medium was extracted with 3 half-volumes of ethyl acetate; the combined extracts were washed once with water and then evaporated. The residue was dissolved in chloroform $(40 \mathrm{ml})$ and applied to a silicic acid column $(1.4 \times 15 \mathrm{~cm})$. The chromatogram was developed with successive $40 \mathrm{ml}$ portions of chloroform/ethyl acetate $(9: 1, v / v),(4: 1, v / v),(1: 1, v / v)$; ethyl acetate; ethyl acetate/acetone $(9: 1, v / v),(4: 1, v / v)$, $(1: 1, \mathrm{v} / \mathrm{v})$ and acetone. The eluate was collected in $10 \mathrm{ml}$ fractions. Examination of the fractions by TLC (system A) showed three aromatic nitro-compounds, A, B and C with $R_{F}$ values of $0 \cdot 31,0 \cdot 24$ and $0 \cdot 17$, respectively. The $R_{F}$ value of chloramphenicol was $0 \cdot 29$. Fractions containing a single compound were pooled and chromatographed again on preparative thin-layer plates. From each plate the predominant fluorescence-quenching band was removed; the product was extracted into acetone and recovered by evaporation.

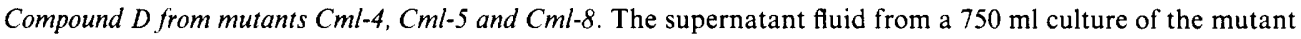
was applied to a column $(2.5 \times 30 \mathrm{~cm})$ of Dowex $50 \times 8\left(\mathrm{H}^{+}\right) 50-100$ mesh and the resin was washed with water $(300 \mathrm{ml})$. Amino acids were eluted with $2 \mathrm{M}$-ammonium hydroxide and fractions that gave a positive reaction for aromatic amines were combined and evaporated. The residue was applied in water $(80 \mathrm{ml})$ to a column $(1.5 \times$ $20 \mathrm{~cm}$ ) of Dowex-50 (pyridinium). The column was developed successively with water $(200 \mathrm{ml}), 0 \cdot 1 \mathrm{M}$-pyridine $(100 \mathrm{ml})$ and $0.5 \mathrm{M}$-pyridine $(100 \mathrm{ml})$ while $5 \mathrm{ml}$ fractions were collected. Aromatic amines were detected by placing a drop from each fraction on filter paper and spraying with $p$-dimethylaminobenzaldehyde. Positive fractions were grouped as a single peak and lyophilized. TLC of the residue gave a single zone that reacted with dimethylaminobenzaldehyde; $R_{F}$ values were 0.23 and 0.27 in systems $\mathrm{C}$ and $\mathrm{D}$, respectively. Mutants $\mathrm{Cml}-4, \mathrm{Cml}-5$ and Cm1-8 each accumulated the same substance which was identical in mobility to authentic $p$-aminophenylalanine. The ${ }^{\mathrm{H}} \mathrm{H}$-NMR spectrum of this substance, recorded in deuterated water at $80 \mathrm{MHz}$ on a Varian model FT- 80 spectrometer with tetramethylsilane in deuterochloroform as the external reference, contained signals matching those given by $p$-aminophenylalanine, at $\delta 2 \cdot 90,3 \cdot 06$ and $3 \cdot 80\left(\mathrm{ABM}, 3 \mathrm{H}, \mathrm{H}-2^{\prime} \mathrm{a}, \mathrm{H}-2^{\prime} \mathrm{b}, \mathrm{H}-3^{\prime}, J_{2^{\prime} \mathrm{a}, 2^{\prime} \mathrm{b}}-15 \cdot 0, J_{2^{\prime} \mathrm{b}, 3^{\prime}}\right.$ $5 \cdot 1 \mathrm{~Hz})$ and at $6.88\left(\mathrm{AA}^{\prime} \mathrm{BB}^{\prime}, 4 \mathrm{H}, \mathrm{H}-2, \mathrm{H}-3, \mathrm{H}-5, \mathrm{H}-6, \Delta v_{\mathrm{AB}} 22 \cdot 2 \mathrm{~Hz}, \mathrm{~N}=J_{\mathrm{AB}}+J_{\mathrm{AB}^{\prime}}=8 \cdot 5 \mathrm{~Hz}\right)$.

Ethanol extraction of mutant cells. Cells were grown in chloramphenicol-production medium for $7 \mathrm{~d}$, harvested by centrifugation and washed with $0.1 \mathrm{M}$-phosphate buffer, $\mathrm{pH} 7 \cdot 0$. They were then resuspended in $70 \%$ ethanol and heated in a water bath at $80^{\circ} \mathrm{C}$ for $10 \mathrm{~min}$. The resulting extract was filtered and examined by TLC in system C.

Hydrolysis of culture supernatant fuids. Concentrated $\mathrm{HCl}(0 \cdot 3 \mathrm{ml})$ was added to $10 \mathrm{ml}$ test tubes containing supernatant fluid $(2 \mathrm{ml})$ from cultures of each mutant grown in chloramphenicol-production medium. The tubes were sealed and placed at $100^{\circ} \mathrm{C}$ for $4 \mathrm{~h}$. After cooling, $1 \mathrm{ml}$ portions were assayed for aromatic amines using the colorimetric procedure of Levine \& Fischbach (1951). The validity of this procedure for measuring $N$-acylated aromatic amines in culture supernatant fluids was established with known amounts of $2(S)$-dichloroacetamido-3( $p$-acetamidophenyl)propan-1-ol.

p-Aminophenylalanine supplementation. An aqueous solution of $p$-aminophenylalanine was sterilized by filtration and added at a final concentration of $1 \mathrm{~mm}$ to $50 \mathrm{ml}$ of chloramphenicol-production medium. The medium then received a vegetative inoculum $(0.5 \mathrm{ml})$ of a mutant strain and the culture was incubated for $7 \mathrm{~d}$. The clarified broth was extracted with ethyl acetate and the extract was examined for chloramphenicol using the colorimetric assay.

Cosynthesis of chloramphenicol. To observe cosynthesis on solid medium, spores from pairs of mutant strains were used to inoculate mixed patches on MYM agar. The cultures were grown until sporulation occurred and the plates were then overlaid with $M$. luteus as described above. To test for cosynthesis in cultures grown in liquid medium, a vegetative inoculum $(0.25 \mathrm{ml})$ of each member of a mutant pair was added to $50 \mathrm{ml}$ of production medium. The cultures were incubated for $7 \mathrm{~d}$ and assayed for chloramphenicol colorimetrically.

\section{RESULTS}

\section{Isolation of mutants}

Approximately 25000 colonies arising from variously mutagenized spores were screened for their ability to produce antibiotics on MYM agar. Twelve showed absolutely no inhibition of the growth of $M$. luteus. These completely nonproducing mutants were isolated at frequencies of 1 in 


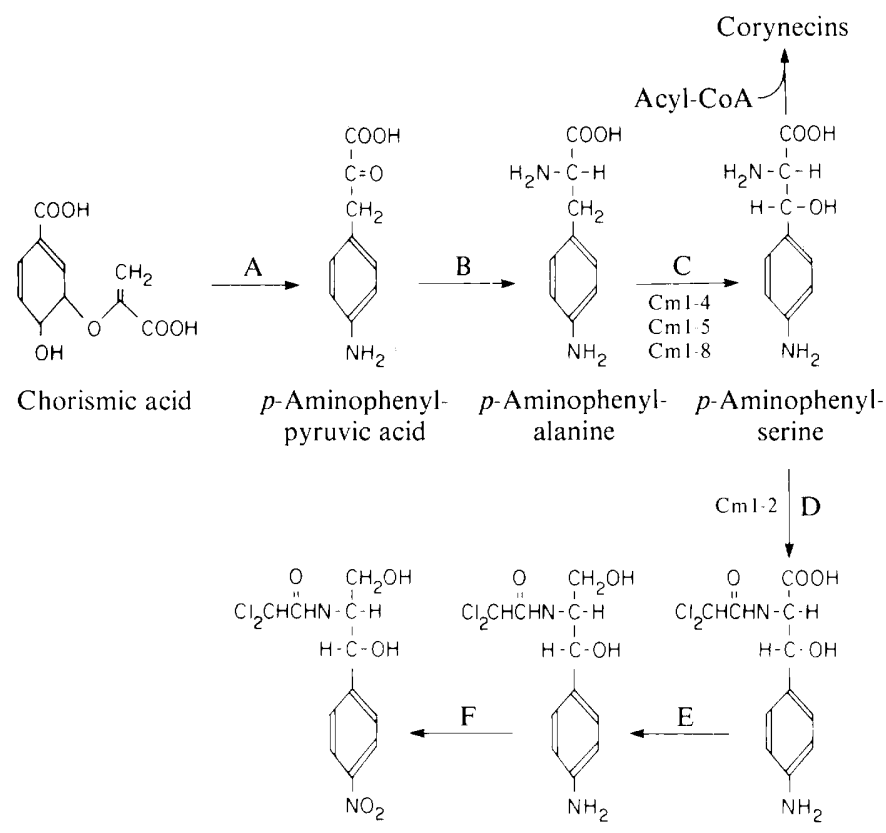

Chloramphenicol

Fig. 1. Biosynthesis of chloramphenicol. Reactions: A, glutaminase, arylamine synthetase; B, aminotransferase; $C$, hydroxylase; $D$, acyl transferase: $E$, reductase; $F$, oxidase. Lesions in mutants $\mathrm{Cml}-1$ and $\mathrm{Cml}-12$ affect reactions $\mathrm{A}$ or $\mathrm{B}$.

Table 1. Production of arylamines and aryl nitro-compounds by chloramphenicol-nonproducing $\left(\mathrm{Cml}^{-}\right)$mutants

$\overbrace{\text { No. }} \begin{aligned} & \text { Mutagen* } \\ & 1 \text { EMS } \\ & 2 \text { EMS } \\ & 3 \text { EMS } \\ & 4 \text { FUV + C } \\ & 5 \text { FUV } \\ & 6 \text { MOP-NUV } \\ & 7 \text { MOP-NUV } \\ & 8 \text { FUV } \\ & 9 \text { FUV } \\ & 10 \text { MOP-NUV } \\ & 11 \text { MOP-NUV } \\ & 12 \text { MOP-NUV }\end{aligned}$

p-Aminophenylalanine

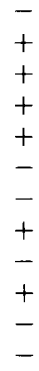

Arylamino-/nitrocompounds excreted

* FUV, far UV, spores plated on MYM agar; FUV + C, far UV, snores plated on MYM + caffeine agar; EMS, ethyl methanesulphonate; MOP-NUV, near UV in the presence of 8 -methoxypsoralen; + , synthesis; - , no synthesis.

approximately 3000 c.f.u. $(0 \cdot 03 \%)$ surviving after mutagenesis with FUV and caffeine; 3 in about 8000 c.f.u. $(0.04 \%)$ after EMS treatment; 5 in about $9000(0.05 \%)$ after NUV + MOP mutagenesis; and 3 in $4500(0.07 \%)$ after exposure to FUV alone. Leaky mutants producing small amounts of chloramphenicol were isolated at frequencies of approximately $0.3 \%$ with each method of mutagenesis. Each of the 12 nonproducing mutants was still prototrophic and grew well on minimal agar. When grown in chloramphenicol-production medium, eight showed no colorimetric reaction for aromatic amino- or nitro-compounds in the clarified culture fluids 
(Table 1). In addition, concentrated extracts of the culture fluids of these eight mutants gave no zones that reacted with $p$-dimethylaminobenzaldehyde after thin-layer silica-gel chromatography. Absorbent paper assay disks soaked with concentrated extracts of the eight culture fluids showed no antibiotic activity against the indicator bacteria.

\section{$\mathrm{Cml}-\mathrm{l}$ and $\mathrm{Cml}-12$}

To determine whether any of these eight strains was blocked in the conversion of chorismic acid to $p$-aminophenylalanine [the arylamine synthetase-catalysed aromatization step that initiates chloramphenicol biosynthesis (Fig. 1)], p-aminophenylalanine was added to the production medium. Two of the strains, $\mathrm{Cml}-1$ and $\mathrm{Cm} 1-12$, then produced chloramphenicol and were presumed to be deficient in arylamine synthetase activity (Jones \& Westlake, 1974).

\section{$\mathrm{Cml}-3$ and $\mathrm{Cml}-10$}

The possibility was considered that some of the six strains (Cm1-3, -6, -7, -9, -10, -11) that did not excrete chloramphenicol or any of its aromatic precursors might accumulate an intermediate that was modified by shunt metabolism so that it escaped detection as an aromatic amino- or nitro-compound. Such a compound, in which the $p$-amino group is acylated, has been described by Wat et al. (1971). We have ascertained that this metabolite has no inhibitory activity against $M$. luteus. To remove acyl groups which might prevent an aromatic amine from being detected, culture fluids were heated under acid conditions. Subsequent colorimetric assay of the hydrolysate failed to detect any aromatic amines excreted by these six mutants.

To determine whether any chloramphenicol intermediates were accumulated intracellularly, ethanol extracts of washed mycelia were examined by thin-layer cellulose chromatography. Cells of two mutant strains, $\mathrm{Cml-3}$ and $\mathrm{Cml-10}$, contained small amounts of an arylamine which had an $R_{F}$ value similar to that of authentic $p$-aminophenylalanine on the same chromatogram. Accumulation of this intermediate, and its failure to promote the formation of chloramphenicol when added as a medium supplement, implicates a pathway lesion after the arylamine synthetase step.

\section{$\mathrm{Cml}-6, \mathrm{Cml}-7, \mathrm{Cml}-9$ and $\mathrm{Cml}-11$}

Extracts of cells of strains $\mathrm{Cm} 1-6, \mathrm{Cml}-7, \mathrm{Cml}-9$ and $\mathrm{Cml}-11$ failed to show any aromatic amino- or nitro-compounds; and, as mentioned above, none excreted any detectable aromatic amine. The possible nature of these mutants is considered in the Discussion.

\section{$\mathrm{Cml}-2$}

Disks permeated with concentrated extracts of culture fluids of strain Cm1-2 showed very weak inhibition of $M$. luteus. This mutant which, along with $\mathrm{Cml-4}, \mathrm{Cml-5}$ and $\mathrm{Cm} 1-8$ (see below), gave a positive response when culture fluids were examined colorimetrically for aromatic nitro- or amino-compounds, was confirmed as an excretor by TLC. Extracts of culture fluids showed three zones that reacted as aromatic nitro-compounds with stannous chloride and $p$-dimethylaminobenzaldehyde and differed in $R_{F}$ value from the zone given by chloramphenicol. Three aromatic nitro-compounds were isolated by silica-gel chromatography of the extracts from culture fluids of $\mathrm{Cml}-2$. The structures of two of the metabolites were identified by comparing their chromatographic behaviour and ${ }^{1} \mathrm{H}-\mathrm{NMR}$ spectra with those of authentic specimens as D-threo-1-p-nitrophenyl-2-propionamido-1,3-propanediol and D-threo-1-p-nitrophenyl-2-isobutyramido-1,3-propanediol. The third product was identical chromatographically to D-threo-1-p-nitrophenyl-2-acetamido-1,3-propanediol ( $R_{F} 0.18$ by TLC) but the amount and purity of the sample were insufficient for NMR spectral identification. Relatively small amounts of $p$-aminophenylalanine were excreted by Cml-2. Mutant $\mathrm{Cml-2}$ therefore appeared to be defective in the reaction that chlorinates the $\mathrm{N}$-acyl group of chloramphenicol (Fig. 1).

\section{$\mathrm{Cml}-4, \mathrm{Cml}-5$ and $\mathrm{Cml}-8$}

Culture filtrates of strains $\mathrm{Cm} 1-4, \mathrm{Cm} 1-5$ and $\mathrm{Cml}-8$ contained a single polar arylamine that could not be extracted into organic solvents. The chromatographic properties of the compound 
accumulated by each mutant were identical and coincided with those of authentic $p$ aminophenylalanine. No $p$-aminophenylserine could be detected. The product from Cml-4 was isolated and was identified as $p$-aminophenylalanine from its NMR spectrum by comparison with an authentic sample. Thus these mutants were probably blocked in the hydroxylation of $p$ aminophenylalanine to $p$-aminophenylserine. It is interesting to note that Akagawa et al. (1979) isolated a mutant which appeared to be blocked in this hydroxylation step but which accumulated deoxychloramphenicol instead of $p$-aminophenylalanine. Our efforts to detect such a compound in cultures of mutants $\mathrm{Cml}-4, \mathrm{Cml}-5$ and $\mathrm{Cml}-8$ were unsuccessful. However, broths of mutants $\mathrm{Cml}-4$ and $\mathrm{Cml}-5$ clarified by centrifugation and then acidified before extraction did yield an aromatic nitro-compound with $R_{F}$ values of 0.55 (system B) and 0.50 (system C) by TLC. This product was tentatively identified as $N$-acetyl-p-nitrophenylalianine by comparison with an authentic specimen ( $R_{F}$ values 0.55 and 0.51 , respectively). Clarified broths of Cml-5 showed an increase in aromatic amine content after acid hydrolysis, suggesting that acylation of the aromatic amino group of $p$-aminophenylalanine had also occurred. Since $2(S)$ dichloroacetamido-3-( $p$-acetamidophenyl)propan-1-ol was not detected by TLC of culture extracts, the product was probably $p$-acetamidophenylalanine or $N$-acetyl- $p$-acetamidophenylalanine.

\section{Cosynthesis}

Attempts were made to detect cosynthesis of chloramphenicol by growing mixtures of mutants in all possible pairwise combinations on agar or in liquid medium. Any chloramphenicol biosynthesis which occurred was expected to result from cosynthesis rather than recombination since mixed cultures of these strains gave recombinant frequencies of $10^{-7}$ per parental c.f.u. or lower (unpublished observation). In agreement with the preceding findings, mutants $\mathrm{Cm} 1-4, \mathrm{Cm} 1-5$ and $\mathrm{Cm} 1-8$ (which accumulated $p$-aminophenylalanine) promoted chloramphenicol synthesis when grown with mutants $\mathrm{Cm} 1-1$ and $\mathrm{Cm} 1-12$ (blocked in the conversion of chorismic acid to $p$-aminophenylalanine). No other instances of cosynthesis were observed.

\section{DISCUSSION}

Radioactive feeding experiments (Westlake \& Vining, 1969) indicated that the sequence of reactions in chloramphenicol biosynthesis following the formation of $p$-aminophenylalanine consists of : hydroxylation at the $\beta$ carbon; substitution of the $\alpha$-amino group; reduction of the carboxyl group to a hydroxymethyl group; and finally, oxidation of the $p$-amino to a $p$-nitro group (Fig. 1). The timing of the chlorination reaction is uncertain but existing evidence has suggested that the halogen atoms are introduced after acylation of the $\alpha$-amino group (Simonsen $e t$ al., 1978). Our isolation of two chloramphenicol-nonproducing mutants (Cm1-1, Cml-12) blocked in the conversion of chorismic acid to $p$-aminophenylalanine, three $(\mathrm{Cm} 1-4, \mathrm{Cm} 1-5$, $\mathrm{Cm} 1-8)$ accumulating $p$-aminophenylalanine, and one $(\mathrm{Cm} 1-2)$ accumulating $\mathrm{D}$-threo-1-pnitrophenyl-2-propionamido-1,3-propanediol and D-threo-1-p-nitrophenyl-2-isobutyramido-1,3propanediol is consistent with the overall pathway. However, the Cm1-2 products are more readily explained if the acyl substituent is chlorinated before attachment to the phenyl propanoid intermediate. In this mutant, absence of the halogenated acylation substrate would allow a low specificity transferase catalysing the acylation reaction to accept less preferred substrates such as acetyl-, propionyl- and isobutyryl-coenzyme A. Shirahata et al. (1972) isolated D-threo-1-p-nitrophenyl-2-acetamido-1,3-propanediol, D-threo-1-p-nitrophenyl-2-propionamido-1,3-propanediol, and D-threo-1-p-nitrophenyl-2-isobutyramido-1,3-propanediol (corynecins 1, 2 and 3, respectively) from cultures of Corynebacterium hydrocarboclastus. Trace amounts of these same compounds have also been reported to accompany chloramphenicol under conditions of antibiotic synthesis by S. venezuelae (Stratton \& Rebstock, 1963).

The failure to obtain mutants accumulating other intermediates might be due to the low specificity of additional enzymes in the pathway. Mutants of Streptomyces aureofaciens blocked at early steps in the pathway of tetracycline biosynthesis produced congeners that retained a high 
level of antibiotic activity (Vaněk et al., 1971). A similar series of events in $S$. venezuelae might have yielded mutant strains that escaped our attention since the initial screening was for absence of antibiotic activity.

Although the four strains (Cml-6, -7, -9, -11) that neither accumulated aromatic intermediates in the chloramphenicol pathway nor responded to $p$-aminophenylalanine might be classified as regulatory mutants, it is possible that some had suffered multi-site mutations. Their phenotype could result from one or more lesions affecting both the reaction sequence catalysed by arylamine synthetase and the reactions converting $p$-aminophenylalanine to chloramphenicol. However, the simultaneous acquisition of two or more independent mutations would be unlikely to give the relatively high proportion of nonexcretors observed. The high incidence of variants altered in chloramphenicol synthesis detected after mutagenic treatments has been seen previously in another strain of $S$. venezuelae, both with and without exposure to intercalating dyes (Michelson \& Vining, 1978). In other streptomycetes high frequency changes in secondary metabolic processes, such as melanin formation, have been shown to accompany changes in DNA sequence organization, especially amplification of specific sequences (Schrempf, 1983). Whether such changes sometimes accompany loss of chloramphenicol production in $S$. venezuelae remains to be seen. Another suggested explanation for the phenotype of these mutants is that they fail to synthesize $p$-aminophenylpyruvic acid which might be an inducer for synthesis of other chloramphenicol biosynthetic enzymes. We could not test this possibility since the putative inducer is too chemically unstable to be synthesized.

This work was supported by operating research grants from the Medical Research Council of Canada and from the Natural Sciences and Engineering Research Council of Canada, and by an Isaak Walton Killam Memorial Scholarship to Janice Doull. We thank D. Smith of the Atlantic Research Laboratory, National Research Council of Canada, for the nuclear magnetic resonance spectra.

\section{REFERENCES}

Aguilar, A. \& Hopwood, D. A. (1982). Determination of methylenomycin A synthesis by the pSV1 plasmid from Streptomyces violaceus-ruber SANK 95570. Journal of General Microbiology 128, 1893-1901.

AHMED, Z. U. \& Vining, L. C. (1983). Evidence for a chromosomal location of the genes coding for chloramphenicol production in Streptomyces venezuelae. Journal of Bacteriology 154, 239-244.

AKagawa, H., OKanishi, M. \& Umezawa, H. (1979). Genetic and biochemical studies of chloramphenicol non-producing mutants of Streptomyces venezuelae carrying a plasmid. Journal of Antibiotics 32, 610620.

Baltz, R. H., Seno, E. T., Stonesifer, J., MatsuSHIMA, P. \& WilD, G. M. (1981). Genetics and biochemistry of tylosin production by Streptomyces fradiae. In Microbiology-1981, pp. 371-375. Edited by D. Schlessinger. Washington, DC: American Society for Microbiology.

Chatterjee, S., Vining, L. C. \& Westlake, D. W. S. (1983). Nutritional requirements for chloramphenicol biosynthesis by Streptomyces venezuelae. Canadian Journal of Microbiology 29, 247-253.

Doull, J. L., Vining, L. C. \& Stuttard, C. (1983). A cryptic plasmid in the chloramphenicol-producing actinomycete, Streptomyces phaeochromogenes. FEMS Microbiology Letters 16, 349-352.

Hayakawa, T., Tanaka, T., Sakaguchi, K., Otake, N. \& Yonehara, H. (1979). A linear plasmid-like DNA in Streptomyces sp. producing lankacidin group antibiotics. Journal of General and Applied Microbiology 25, 255-260.
Jones, A. \& Westlake, D. W. S. (1974). Regulation of chloramphenicol synthesis in Streptomyces $\mathrm{sp}$. 3022a. Properties of arylamine synthetase, an enzyme involved in antibiotic biosynthesis. Canadian Journal of Microbiology 20, 1599-1611.

KIRBY, R. \& HoPwOOD, D. A. (1977). Genetic determination of methylenomycin synthesis by the SCP1 plasmid of Streptomyces coelicolor A3(2). Journal of General Microbiology 98, 239-252.

LeVine, J. \& Fischbach, H. (1951). The chemical determination of chloramphenicol in biological materials. Antibiotics and Chemotherapy 1, 59-62.

MaLiK, V. S. \& Vining, L. C. (1970). Metabolism of chloramphenicol by the producing organism. Canadian Journal of Microbiology 16, 173-179.

McGrath, R., Vining, L. C., Sala, F. \& Westlake, D. W. S. (1968). Biosynthesis of chloramphenicol. III. Phenylpropanoid intermediates. Canadian Journal of Biochemistry 46, 587-594.

Michelson, A. M. \& Vining, L. C. (1978). Loss of chloramphenicol production in strains of Streptomyces species 3022a treated with acriflavine and ethidium bromide. Canadian Journal of Microbiology 24, 662-669.

OCHI, K. \& KaTz, E. (1980). Genetic analysis of the actinomycin-producing determinants (plasmid) in Streptomyces parvulus using the protoplast fusion technique. Canadian Journal of Microbiology 26, 1460-1464.

SCHREMPF, H. (1983). Reiterated sequences within the genome of Streptomyces. In Genetic Rearrangement, Fifth John Innes Symposium, pp. 131-142. Edited by K. F. Chater, C. A. Cullis, D. A. Hopwood, A. W. B. 
Johnston \& H. W. Woolhouse. London: Croom Helm.

Shirahata, K., Hayashi, T., Deguchi, T., Suzuki, T. \& MATSUBARA, I. (1972). The structures of corynecins; chloramphenicol analogues produced by a $\mathrm{n}$ paraffin-grown bacterium. Agricultural and Biological Chemistry 36, 2229-2232.

Simonsen, J. N., Paramasigamani, K., Vining, L. C., MCINNes, A. C., Walter, J. A. \& WRight, J. L. C. (1978). Biosynthesis of chloramphenicol: studies on the origin of the dichloroacetyl moiety. Canadian Journal of Microbiology 24, 136-142.

Stratton, C. D. \& Rebstock, M. C. (1963). A new metabolite of Streptomyces venezuelae: D-threo-1-paminophenyl-2-dichloroacetamido-1,3-propanediol. Achives of Biochemistry and Biophysics 103, 159-163.

StutTaRD, C. (1982). Temperate phages of Streptomyces venezuelae: lysogeny and host specificity shown by phages SV1 and SV2. Journal of General Microbiology 128, 115-121.

VaněK, Z., Cudlín, J., Blumauerová, M. \& HošŤALEK, Z. (1971). How many genes are required for the synthesis of chlortetracycline? Folia Microbiologica 16, 225-240.
Wat, C.-K., Malik, V. S. \& Vining, L. C. (1971). Isolation of 2(S)-dichloroacetamido-3-( $p$-acetamidophenyl)propan-1-ol from a chloramphenicol-producing Streptomyces species. Canadian Journal of Chemistry 49, 3653-3656.

WebER, J. M., WiERMAN, C. K., HutChinSON, C. R., WANG, Y.-G. \& Davies, J. (1982). Genetics and biochemistry of erythromycin production in Streptomyces erythreus NRRL2338. Trends in Antibiotic Research. Genetics, Biosyntheses, Actions and New Substances, pp. 55-64. Edited by H. Umezawa, A. L. Demain, T. Hata \& C. R. Hutchison. Tokyo, Japan: Antibiotics Research Association.

Westlake, D. W. S. \& Vining, L. C. (1969). Biosynthesis of chloramphenicol. Biotechnology and Bioengineering 11, 1125-1134.

Xue, Y., Dong, K., LI, M. \& ZHU, Y. (1978). Genetic evidence of the presence of plasmid in Streptomyces griseus and its relationship with the biosynthesis of streptomycin. Acta microbiologica sinica 18, 195-201.

Zippel, M., Neigenfind, M. \& NoACK, D. (1983). Possible plasmid involvement in turimycin production in Streptomyces hygroscopicus. Molecular and General Genetics 192, 471-476. 